\title{
No hay noticias buenas ni malas... Sólo noticias que interesan $\mathbf{o}$ no $^{\mathbf{t}}$
}

\author{
Julio Estremadoyro Alegre \\ Departamento Académico de Comunicación Social
}

- Dos buenas noticias para los intereses peruanos surgieron ajer en Sao Paulo (sección Deporte Total de El Comercio, viernes I de nov. 2002)

- Esta mañana tenemos dos noticias buenas y una mala (Conductores de Radioprogramas, en la secuencia Ampliación de Noticias, edición del 30 de octubre 2002)

- No tratar de ocultar las malas noticias. Cualquier organización puede ser victima de un acontecimiento fortuito o de un error que origine noticias desfavorables a la misma (Nielander, William: "Práctica de Relaciones Públicas". p. (72)

Uso muy común es referirse a noticias buenas, malas, positivas, negativas. Hasta periodistas consagrados hacen uso de esa nomenclatura.

Se confunde el suceso y ei hecho con el resultado de la cobertura periodtstica del mismo. Es decir, con la noticia y su correspondiente información que dan cuenta de lo acontecido. Los hechos pueden ser negativos, positivos o neutros; o, también, según otra apreciación, buenos o malos. Pero, en periodismo los hechos son interesantes a no y la información sobre ellos puede es correcta ( objetiva, veraz, imparcial, honesta y responsable) $o$ no. En consecuencia, no hay noticias positivas, negativas, buenas o malas; sólo hay noticias que interesan y su información es correcta.

Esta confusión explica desde el origen de la historia porqué los mensajeros portadores de noticias sobre sucesos desafortunados, negativos y malos eran ejecutados. A los infelices mensajeros se les atribuia conexión con el suceso indeseable.

1 Capitulo del libro en preparación Lecciones de periodismo de television. 
No es difícil entender, entonces, porqué los gobiernos asediados por sus desaciertos o ocurrencias negativas suelen denunciar a los periodistas y medios de comunicación como los causantes de las crisis o inestabilidades politicas que los hechos originan. "Dan sólo noticias negativas" claman los voceros gubernamentales.

También es fácil de entender porqué en los regimenes dictatoriales - de izquierda y derecha- no se permite la libre información. En esos regímenes son inconcebibles medios y periodistas que aborden los hechos y sucesos que no agradan a los gobernantes.

Queda, pues, claramente establecido que los periodistas y medios no originan los sucesos. Dan cuenta de ellos. Pero, a este respecto, conviene precisar bien que la información que se brinda, como se ha indicado, tiene que ser correcta. Es decir:

a) Objetiva ( no se debeopinar cuando se dan los detalles de los hechos);

b) Veraz ( todo lo que se informedebe ser la verdad estricta y confirmada);

c) Imparcial ( se debe dar oportunidad a todas las partes involucradas a expresar sus razones b a referirse a todos los ángulos informativos);

d) Honesta ( no se debe magnificar o insistir sólo en los aspectos negativos de un suceso, con una clara y perversa intencionalidad);

e) Responsable ( no debe infâmar o atribuir conductas delictivas por simples afirmaciones o versiones sin pruebas $\mathrm{y}^{\prime \prime}$ 's in sanción judicial).

Pero la noticia, que La noticia es el resultado de la cobertura periodística de un suceso que tienen interés general, que interesa al mayor número de personas, debe ser, en consecuencia, interesante. Si no lo es, si el suceso abordado no despierta ningún atractivo .o inquietud, no tendrá lectores, radioescuchas o televidentes, según sea el medio.

Un millonario norteamericano, cansado de los diarios que, según él, sólo dan noticias negativas y malas, decidió fundar un periódico que únicamente diera noticias positivas, buenas y alentadoras. Antes de los tres meses tuvo que cerrar la publicación por falta de tiraje, lo que le ocasionaba diariamente fuertes pérdidas que amenazaban acabar con su fortuna. Explicación: el diario del millonario daba noticias que no interesaban a los potenciales lectores. 


\section{Información y noticia}

Como se ha indicado, un hecho o suceso sólo es noticia cuando tiene cobertura y conocimiento periodisticos. Algo puede ocurrir y permanecer oculto durante mucho tiempo. Será noticia cuando un reportero lo descubra o cuando el periodismo tome conocimiento de lo sucedido. Recuérdese el caso del profesor y los alumnos de La Cantuta. El asesinato fue noticia sólo cuando, muchos meses después, se descubrieron los restos de las victimas.

Académicamente, no es lo mismo noticia que información, aunque en la conversación diaria se les use indistintamente para referirse al contenido de los noticieros.

Noticia e información son dos momentos de un mismo proceso, ya que, como se ha indicado, noticia es el resultado de la acción del reportero en el lugar de los hechos e información es la elaboración, de acuerdo con el lenguaje de cada medio, del informe de los detalles del suceso.

Reporteros de un diario, radio y televisión pueden acudir a cubrir un acontecimiento. Los tres tendrán la misma noticia, pero sus informaciones serán diferentes porque el primero se preocupará de la redacción de su texto, el segundo de su informe oral, el tercero de sujetar su narración a las imágenes, los sonidos y el movimiento captados.

Para entender mejor que noticia e información no son lo mismo, se pueden considerar estos dos ejemplos, con connotaciones muy diferentes: risuefia y dramática.

El director de un diario ubicó al hijo renuente de seguir estudios universitarios de un matrimonio amigo en la Sección Deportes por la afición del joven a los mismos. Su primera comisión fue la cobertura del primer partido de un triplete en el Estadio Nacional. El jovencito acudió al estadio - lugar del hecho- y, terminado el partido, se fue a su casa con el conocimiento del resultado o noticia. Por la noche, en el cierre de edición el jefe de la sección preguntó: ¿ dónde está la información del primer partido?. Todos sabłan el resultado, pero había que dar los detalles. Le dijeron que el jovencito no la habia dejado. Entonces el jefe ordenó que lo llamaran por teléfono. En el contacto, el jovencito contestó: ¿Qué información?... si no pasó nada...... ¡el partido terminó cero a cero! 
Un ómnibus interprovincial se precipitó al abismo en Pasamayo. Un canal de televisión encargó la cobertura de emergencia a un equipo integrado por el reportero, el camarógrafo y el chofer-ayudante. El equipo hizo la cobertura del caso, grabando las imágenes correspondientes. Luego se dirigió al hospital de Huaral, donde habian sido llevados los heridos. Desde ahi, el reportero llamó al canal para dar la noticia a su jefe: "Hay 25 muertos y 48 heridos que viajaban en el ómnibus de la agencia " $x$ " rumbo a Trujillo. Ya vamos con las imágenesimágenes" (es decir, la información). Al regresar a gran velocidad para alcanzar la edición del noticiero, se rompió la dirección del carro y pasaron a la pista contraria. Sucedió la tragedia: un gigantesco camión ómnibus arrolló al vehiculo de la televisora y lo arrastró casi 80 metros. En el acto murieron los tres ocupantes y los equipos quedaron destrozados. Nunca llegó la información acerca del ómnibus de Pasamayo al canal, aunque ya el reportero habia comunicadose tenia la noticia.

\section{El sentido de la noticia}

Las noticias no tienen un valor periodístico absoluto. Dependen de varias condiciones. Estas pueden ser: a) por la nomenclatura noticiosa del Medio (es distinto el concepto informativo de "El Comercio" que el de un diario "chicha"); b) por la oportunidad (cuando hay tensión en la opinión pública por determinados sucesos uno nuevo interesará mucho); y, c) por el panorama del día (a veces hay sucésos ide granampactô que minimizan otras ocurrencias normalmente interesantes)e Puccinelli Converso»

Ahora bien, diariamente se producen miles de hechos. Sin embargo, sólo unas pocas decenas merecerán la atención periodística, fundamentalmente por la limitada capacidad de cobertura que tienen los medios.

En el periodismo norteamericano se distinguen dos clases de noticias: las "hardnews" y las "softnews", siendo las primeras las coberturas de sucesos de gran impacto y de urgente actualidad, y las segundas de actualidad mediata o latente ya que no son coberturas de sucesos o acontecimientos.

Pero, $\measuredangle$ cómo se pueden diferenciar los sucesos para dar cobertura a unos y a otros no?. Por una expresión que constituye en el periodismo una exigencia fundamental y eliminatoria: el sentido de la noticia. Es decir la capacidad que tienen los periodistas para determinar qué sucesos tienen más interés para sus lectores, radioescuchas o televidentes. 
Si se quisiera hacer alguna referencia comparativa para explicar mejor lo que significa no tener el sentido de la noticia se puede indicar que es como la incapacidad de un daltónico para distinguir las luces de un semáforo, el pulso nervioso y agitado para un cirujano, las limitaciones de un manco para ser boxeador.

El periodista o comunicador que carezca del sentido de la noticia ha equivocado de profesión y mas le valiera dedicarse a otra actividad, ya que en el exigente e implacable mundo de las noticias será poco menos que un fracaso o un incompetente, permanentemente frustrado.

Sin embargo, es muy improbable que se carezca absolutamente de esa cualidad. Es cierto que algunos periodistas vienen dotados de un admirable y preciso sentido de la noticia, pero también es cierto que eEl sentido de la noticia puede desarrollarse y ejercitarse con la práctica.

Para ello es indispensable considerar y teniendo en cuenta los tequisitos indispensables de una noticia. Estos son:

\section{Actualidad}

Un suceso para ser noticia debe tener actualidad. Es decir, ser algo que acaba de ocurrir. Y en esto reside fundamentalmente la diferencia entre Historia y Periodismo, ya que la Jistoria se ocupa de sucesos ocurridos hace mucho tiempo. Una noticia tiene una vigencia de minutos ( radio y agencias de noticias); horas ( televisión) y un día (diarios). Si una noticia se da luego de esa vigencia - en inglés se dice deadline- ya resulta un refrito, en el argot periodistico. Es decir, algo ya conocido y sabido.

\section{Novedad}

Pero el suceso debe tener novedad. Es decir, el suceso tiene que haber ocurrido por primera vez. O si vuelve a ocurrir debe mostrar facetas nuevas. De no ser así entonces perderá su valor noticioso. Por ejemplo, un embotellamiento vehicular producido por un semáforo en mal estado. Cuando se informa por primera vez puede ser una noticia impactante. Pero si el embotellamiento persiste por dias, entonces el suceso irá perdiendo impacto, novedad. Esto explica porqué en periodismo lo reiterativo no interesa. 
Es el requisito más importante para fortalecer y ejercitar el sentido de la noticia.

No todos los sucesos, pese a ocurrir en el día y mostrar novedad, son dignos de cobertura periodistica. Para ello, deben mostrar tales características que provoquen el interés del mayor número de personas, como ya se ha indicado. Es decir, el suceso debe tener interés general. Y esta es la exigencia más decisiva para definir el valor noticioso de un suceso.

Como se sabe, tener la capacidad de determinar si un suceso tiene interés general es el requisito fundamental para un periodista. $Y$ se ha reiterado que a eso se llama poseer sentido de la noticia.

Esa capacidadel periodistica sentido de la noticia - es decir, la determinación del interés general del suceso - estả más o menos latente, como se adelantó, en cada persona. $\mathrm{Y}$ puede ser desarrollado o perfeccionado, mediante el conocimiento de los factores que debe mostrar el suceso para ser interesante. Estos son los siguientes:

\section{Prominencia}

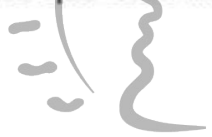

El primer factor eslaiprominencia Toptularidad de los personajes que

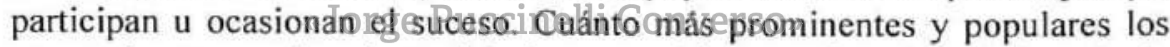
personajes mayor interés tendrá el suceso. Algunos ejemplos: la llegada de Madonna a Lima tendrá más interés que la de Alejandra y la de ésta más que la de una cantante poco conocida. El suicidio de un desconocido tendrá menos impacto que el de una estrella televisiva. La declaración de un congresista cederá ante la del presidente.

\section{Importancia}

Otro factor es la importancia del suceso. La ley que crea la regionalización en el país, la firma del acuerdo final de paz con el Ecuador destacan por su importancia y trascendencia. $Y$ aqui hay que hacer una reflexión entre importancia e interés, porque a veces se confunden. No todo lo importante es interesante. Por ejemplo, la promulgación de un dispositivo que favorecerá la exploración minera, puede ser muy importante para la economía del país, pero no necesariamente tendrá interés para el mayor número de personas. Esta precisión es muy 
necesaria para no caer en una labor informativa trascendentalista, que podría ser poco interesante -de hecho lo es, por la experiencia al respecto-. Muchos fracasos periodísticos han tenido su explicación en esa tentación de guiarse más por la importancia que por el interés.

\section{Proximidad}

Un tercer factor es la proximidad del hecho o el suceso. Nos interesa más lo que está más cerca de nosotrosuno. Un accidente en Lima interesará más a los peruanos que uno similar ocurtido en Quito. No así a los ecuatorianos. A este respecto, hay que indicar que hay dos clases de proximidades: la geográfica y la cultural. Esta última explica por qué un suceso ocurrido en París, Londres o Madrid interese más que otro similar ocurrido en Tegucigalpa o Belice. $Y$ esto por la sencilla razón de que estamos más informados y enterados por distintos medios (cine; televisión, periódicos, novelas, etc.) de acontecimientos ocurridos en las ciudades europeas que en algunas latinoamericanas.

Magnitud

Un cuarto factor es la magnitud del hecho. Vale decir cuánto está involucrado en el hecho, cuantitativa y cualitativamente. Un accidente con un muerto interesará menos que otros con 50 . Un temblor menos que un terremoto. Una lotería de mil dólares menos que otra de un millón. Un pequeño accidente del Papa que un atentado contra su vidac.

\section{Circunstancia}

"Jorge Puccinelli Converso»

Un quinto factor para determinar el interés general de la noticia es la circunstancia en que se produjo el suceso. Tiene mayor impacto que un corredor de autos muera en plena competencia, que en un accidente carretero cualquiera. Que un asalto se produzca a plena luz del sol, frente a una comisaria, que un asalto en la oscuridad en un sitio alejado. Que la princess Diana muera, con su acompafiante sentimental, al estrellarse su vehiculo, manejado por un chofer beodo en una vía parisina, al ser perseguida por paparazzi, en lugar de, por decir una circunstancia, fallecer al rodar las escaleras de su palacio.

Interés humano

Otro factor del interḱs general es el caso humano que, por lo general, provoca emociones y hasta lágrimas en el público. En ocasiones motiva hasta 
un gran espíritu de solidaridad. Se trata de la presentación de historias de personas que no gozan de prominencia periodística en el momento de la cobertura. Posteriormente, por la difusión del caso, pueden ser muy conocidas. Tal el caso de la humilde madre campesina que caminó decenas de kilometros en la nieve para poder salvar a su bebito, con graves quemaduras. O del pequeño lustrabotas de 8 años que trabaja doce horas para poder ayudar a su madre enferma y hermanitos, abandonados por el padre.

\section{Singularidad o rareza}

Es el último factor de interés general. Se trata de noticias insólitas, desusadas, originales que provocan, por lo común, una sonrisa, mucha simpatia y no poca admiración y relax. Tal es el caso de los ganadores de grandes loterías, el de las localidades donde mandan y predominan las mujeres, el de la perrita que amamanta gatitos, etc. etc.

Hay que señalar que un suceso despertará mayor interés general si en él rigen varios de los factores descritos. Recordemos, por ejemplo, la muerte de la princesa Diana que conmovió a millones de personas en el mundo entero. En este episodio jugaron los siguientes factores: prominencia (era la mujer más famosa de su tiempo); la importancia (un hecho que afectaba a la realeza británica con alguna connotación religiosa y racial), la proximidad cultural ( el hecho ocurrió en Paris); la circunstancia (ya descrita y la más importante en este caso); el interés humano (se trătabai detuna princesa enamôtada).

\section{"Jorge Puccinelli Converso»}

Tres ejercicios

Para fortalecer y desarrollar el sentido de la noticia se puede practicar tres ejercicios. Son los siguientes:

- Ejercicio de Jerarquización.- Se considera noticias independientes, reales o imaginarias, y se trata de ordenarlas de acuerdo con su mayor o menor interés general. Es decir, colocando en el primer lugar la noticia más impactante, luego la que le sigue en interés y así, sucesivamente. Cuando se termine el ejercicio la última noticia debe ser la menos interesante.

- Ejercicio de Selección.- En todo suceso hay muchos detalles a considerarse, por lo que el periodista tiene que determinar a seleccionar qué 
aspectos son los más interesantes. Este ejercicio capacita en esa habilidad. Se aplica sobre todo para las extensas exposiciones(mensajes a la nación, discursos, conferencias de prensa, declaraciones, comunicados, etc).

- Ejercicio del Interés Creciente.- Por lo general aborda casos imaginarios o inventados. Se trata de presentar un hecho o suceso muy elementalmente. $Y$ luego, en varios pasos, ir agregando al hecho o suceso factores del interés general que provoquen una noticia del mayor impacto.

\section{Conclusiones}

1. No se debe confundir los sucesos con las noticias de los mismos.

2. Lo hechos son los que pueden ser negativos, positivos, buenos o malos.

3. Las noticias sólo dan cuenta de los sucesos.

4. Las noticias deben interesar y tener un enfoque correcto.

5. Noticia e información son dos momentos distintos de un mismo proceso.

6. No todos los sucesos merecen cobertura periodística: sólo los que pueden interesar al mayor número de personas.

7. El sentido de la noticia permite determinar el interés de los sucesos.

8. Los periodistas deben tener un buen sentido de la noticia para tener éxito.

9. El sentido de la noticia se puede desarrollar y ejercitar.

10. Los factores del interés general de los sucésos facilitan la sólida formación del sentido de la noticia. 


\section{BIBLIOGRAFIA}

CBS NEWS: Técnicas de las noticias en TV. Trillas. México. 1968.

ESTREMADOYRO, Julio: Periodismo de televisión. Centro de Reproducción de Documentos de la USMP. Lima. 2000.

FANG, Irving: Noticias por televisión. Ediciones Marymar. Buenos Aires. 1977.

FOX, William: Wrinting the News: Print Journalisma in the Electronic Age. Nueva York. Hastings House, 1987.

NIELANDER, William: Práctica de Relaciones Públicas. Hispano Europea. Barcelona.1973.

PORTER, Philip: El Reporteroy las noticias. Habana Cultural. Cuba. 1943.

WOOD, William: Periodismoelectrónico. Editorial Letras. México. 1969.

YORKE, Ivor: La técnica de las noticias por TV. Focal Press. 1991.

\section{Biblioteca de Letras "Jorge Puccinelli Converso"}

